\title{
A reforma do ensino superior no contexto da reforma do estado brasileiro
}

\author{
Maria Rejane Lima Brandim*, Marina Graziela Feldmann** \\ Universidade do Minho/Pontifícia Universidade Católica de São Paulo-PUC/SP, ** Pontifícia Universidade Católica de São \\ Paulo-PUC/SP
}

\begin{abstract}
Resumo
A Reforma do Estado brasileiro estabelecida nos anos 90 é representada pelo ajuste fiscal e a implantação de um Estado mínimo. Na década seguinte ela é marcada pelas diretrizes dos organismos internacionais do capital. Nesse contexto, passou a ser institucionalizada a reforma do ensino superior, configurada pelo Reuni. Nesta pesquisa bibliográfica, caracterizamos a política para o ensino superior brasileiro a partir de tais reformas. Buscamos identificar um processo de democratização do ensino. Nossos estudos apontam para um aumento de instituições federais, matrículas e contratação de docentes. Identificamos problemas relativos à estrutura física e pedagógica nas Universidades e ao trabalho docente.

Palavras-chave: Reforma do Estado brasileiro, Reforma do Ensino Superior brasileiro, Reuni.
\end{abstract}

\section{Metodologia}

Este estudo partiu da análise bibliográfica sobre o Reforma do Ensino Superior brasileiro no contexto da Reforma do Estado, principalmente no que diz respeito a caracterização do Programa de Apoio aos Planos de Reestruturação e Expansão das Universidades Federais (REUNI). Nele procuramos identificar as características da política para o ensino superior no Brasil, seus objetivos e princípios, na perspectiva de identificação da democratização do acesso ao ensino superior no Brasil. Dessa forma procedemos à leitura de material já escrito sobre a reforma do estado brasileiro iniciadas nos anos 90, sobre a reforma do ensino superior configurada neste contexto, nos anos de 2002 a 2012 e sobre o Reuni.

Para Lakatos e Marconi (2003) a pesquisa bibliográfica consiste do levantamento, seleção e documentação de toda bibliografia já publicada sobre o assunto que está sendo pesquisado, em livros, revistas, jornais, boletins, monografias, teses, dissertações, material cartográfico, com o objetivo de colocar o pesquisador em contato direto com todo material já escrito sobre o mesmo. Gil (2008) complementa e afirma que embora em quase todos os estudos seja exigido algum tipo de trabalho desta natureza, há pesquisas desenvolvidas exclusivamente a partir de fontes bibliográficas.

Gil (2008) destaca ainda que a principal vantagem da pesquisa bibliográfica é a de permitir ao investigador a cobertura de uma gama de fenômenos muito mais ampla do que aquela que poderia pesquisar diretamente de uma vez que alguns problemas de pesquisa requerem dados muito dispersos.

\section{A Reforma do Estado brasileiro}

É no âmbito da crise global do sistema capitalista e nas estratégias de recomposição e reestruturação produtiva, estabelecidas a partir do início dos anos 90 do século XX, que se situa a Reforma do Estado brasileiro, sob a ofensiva ideológica do neoliberalismo.

Neste momento tem inicio um amplo retrocesso no que diz respeito aos direitos sociais conquistados e declarados na Constituição Federal de 1988. O desmonte do Estado brasileiro se dará através de "reformas" orientadas e monitoradas pelos organismos internacionais tais como o Banco Mundial, a Organização Mundial do Comércio e o Fundo Monetário Internacional, atreladas às novas exigências do capital mundializado, no fim do século $\mathrm{XX}$, em resposta à crise que o mesmo entrou ao início da década de 1970.

A primeira geração de reformas do estado brasileiro foi iniciada no governo Collor de Melo. A proposta de reforma tem origem na constatação do esgotamento financeiro do estado e na necessidade de redução do déficit público. Ao analisar esta reforma, Almeida (2010, p. 27) conclui:

$\mathrm{O}$ enxugamento da máquina estatal a partir da eliminação de superposições constituíram-se em objetivos da reforma administrativa. O eixo do discurso governamental sustentava-se no tripé desastização, desregulamentação e liberalização dos preços e salário.

Marcado por escândalos de corrupção, o Governo Collor de Melo é ineficaz na condução da reforma do Estado ainda que, no período de 1990 a 1991, tenham sido lançados sucessivamente os Plano Collor e Plano Collor II e o Plano de Reconstrução Nacional. Após a renuncia de Fernando Collor, Itamar Franco assume o governo com a função de devolver a estabilidade econômica e politica necessárias á governabilidade do país, implantando para isso uma reforma monetária, estabelecida pelo então Ministro da Fazenda, Fernando Henrique Cardoso.

Ao assumir a presidência em 1995, Fernando Henrique Cardoso, também configura o seu plano de governo em torno do diagnóstico da falência do Estado nacional-desenvolvimentista, implementando ao longo de dois mandatos presidenciais, uma Reforma do Estado. Esta reforma representa o ápice da ascensão e consolidação das políticas neoliberais no país, que proclamam o total desmonte do Estado Benfeitor. Nesse sentido, as características mais marcantes do ideário neoliberal são, de um lado, a implantação de um 
Estado mínimo em sua intervenção socioeconômica, possibilitando um caminho livre para o crescimento do mercado; o forte ajuste fiscal com a redução de impostos sobre rendimentos altos e as grandes fortunas; e, de outro lado, o estabelecimento de um Estado Máximo, para conter a força dos sindicatos e promover a sua desestabilização e enfraquecimento diante das demandas das classes trabalhadoras, com a diminuição ou corte nos gastos públicos e a progressiva privatização de empresas estatais e de serviços públicos de uma maneira geral.

As reformas iniciadas e/ou implantadas nos Governos Collor de Melo e Fernando Henrique Cardoso, trazem a tona a possibilidade de "transformação da agenda neoliberal em plano de governo." (Almeida, 2010, p. 34). Concordamos com Leher (2006, p. 24) que nestas reformas

O ajuste estrutural que desmonta o precário Estado Social é feito em nome da globalização, um processo apresentado como inexorável e irresistível, contra o qual nada é possível fazer, a não ser se adaptar, mesmo que às custas de exponencial desemprego, privatizações selvagens, crise cambial, aumento da taxa de juros e destruição dos direitos do trabalho.

A segunda geração de reformas acontece nos anos do governo de Lula da Silva, numa expressiva complementaridade às reformas iniciadas no governo anterior. Ainda que com menos intensidade, estas se mostram contrárias às necessidades das classes que vivem do trabalho e fortemente marcadas pelas recomendações, diretrizes e ditames dos organismos financeiros internacionais, tais como o Banco Mundial e o Fundo Monetário Internacional.

\section{A Reforma do Ensino Superior no Brasil}

Durante os dois mandatos presidenciais de Fernando Henrique Cardoso, no período de 1995 a 2002, a proposta de governo para a educação foi marcada pelo papel econômico que esta deveria assumir. A educação passa a ser vista como referência para o necessário desenvolvimento económico brasileiro, com base no progresso científico e tecnológico. Cunha (2003, p. 38) aponta que:

Essa indução atuaria no sistema educacional pelo topo, isto é, pela universidade, entendendo-se que a competência científica e tecnológica é fundamental para garantir a qualidade do ensino básico, secundário e técnico, assim como aumentar a qualificação geral da população. Para se conseguir isso, a proposta afirmava a necessidade de se estabelecer uma "verdadeira parceria" entre setor privado e governo, entre universidade e indústria, tanto na gestão quanto no financiamento do sistema brasileiro de desenvolvimento científico e tecnológico.

Nesta perspectiva, a política para o ensino superior ensejada por este governo, teve um caráter fortemente marcado pelo desmantelamento do sistema federal de ensino superior com vistas a racionalização técnica e a mercantilização com marcas claras de incentivo ao produtivismo acadêmico:
A política para o ensino superior deveria promover uma "revolução administrativa": o objetivo seria a administração mais racional dos recursos e a utilização da capacidade ociosa, visando a generalizar os cursos noturnos e aumentar as matrículas, sem despesas adicionais. Para isso, as universidades deveriam ter uma "efetiva autonomia", mas que condicionasse o montante de verbas que viessem a receber à avaliação de desempenho. Nessa avaliação, seriam levados em conta, especialmente, o número de estudantes efetivamente formados, as pesquisas realizadas e os serviços prestados. A racionalização dos gastos e o aumento da produtividade deveriam se refletir em aumentos salariais de professores e de funcionários. (Cunha, 2003, p. 39)

A Reforma da Educação Superior do governo Lula da Silva referenda-se nas propostas do Banco Mundial para as universidades dos países chamados periféricos, destacadas nos documentos "La enseñanza superior: las lecciones derivadas de la experiência" publicado em 1995 e "Educación Superior en los Países en Desarrollo: Peligros y Promesas" publicado em 2000, que determinam, entre outras coisas, que o ensino efetivado nas universidades dos países pobres é caro e inadequado às suas necessidades sociais. Não é de estranhar que o Banco Mundial recomende para os países subdesenvolvidos um modelo universitário com a diversificação da educação superior (criação de Centros Universitários e Cursos Sequenciais, por exemplo), com pouca ênfase na pesquisa, visando antes a formação profissional e tecnológica em cursos de duração de até 04 anos e a expansão via educação a distância, além da busca de autonomia financeira por parte das universidades:

Considerando as estratégias e opções para melhorar os resultados dos sistemas de ensino pós-secundário, o estudo centra-se em quatro principais diretrizes para a reforma: a promoção de mais tipos de instituições públicas e privadas; a provisão de incentivos que levem as instituições públicas a diversificar as suas fontes de financiamento; a redefinição do papel do estado, com especial atenção para a autonomia e responsabilidade institucional e a adoção de políticas que enfatizam a qualidade e equidade. (Banco Mundial,1995, p. 08).

A proposta do Banco Mundial deixa clara a perspectiva do estabelecimento da ideologia da globalização, em que o debate educacional é pautado em grande parte pela estratégia politica e pelo mercado, por isso gastar com ensino superior e pesquisa nos países em desenvolvimento não é uma alternativa, muito menos uma prioridade.

O mundo em desenvolvimento está reagindo rapidamente a este fenómeno, em que a educação é uma preocupação política de primeira ordem. O capital humano de alta qualidade se desenvolve muito bem qualificado nos sistemas de ensino, em que a educação terciária as ministra as habilidades avançadas mais desejadas atualmente no campo do trabalho. $\mathrm{Na}$ maioria dos países desenvolvidos 
aumentou substancialmente a proporção de jovens que recebem ensino superior, e também se está recorrendo a aprendizagem ao longo da vida para ajudar os trabalhadores adultos se adaptar a essas economias em rápida transformação. (Banco Mundial, 2000, p. 17)

Ao discutir a passividade do governo brasileiro frente as orientações do Banco Mundial, Leher (2006, p. 28) alertava que este:

(...) apregoa uma maior diferenciação no ensino superior, demandando a supressão da indissociabilidade entre o ensino e a pesquisa, nos termos do Decreto 2306/97 que distingue as instituições de ensino superior universitárias e os centros universitários, um eufemismo para legitimar as universidades exclusivamente de ensino, como poderá acontecer com a criação de universidades por área do conhecimento (...) como já ocorre nas instituições privadas. O Banco indica os instrumentos para a implementação dessa política, enfatizando a importância de redefinir a autonomia universitária em moldes neoliberais, a saber, uma autonomia que signifique o afastamento do Estado da vida da instituição.

A Reforma da Educação Superior do governo Lula da Silva teve inicio em 2003, quando foi instituido o Grupo de Trabalho Interministerial (GTI) que tinha como função analisar a situação da educação superior brasileira para apresentar um plano de ação visando a reestruturação, desenvolvimento e democratização das Instituições Federais de Ensino Superior (IFES).

O relatório final do GTI composto de quatro partes, aponta um plano dividido em quatro etapas: a) ações emergenciais; b) autonomia universitária; c) complementação de recursos (financiamento) e d) a implementação da Reforma Universitária.

O documento ainda reconhece "a situação de crise da educação superior brasileira, em especial das universidades federais, mas atribui o problema à crise fiscal do Estado, sem maiores aprofundamentos de sua origem." (Otranto, 2006, p.43)

Ao analisar o contexto para a reforma do ensino superior no Governo Lula da Silva, Mancebo (2004, p. 849) aponta:

(...) o governo herdou, de um modo geral, uma intensa desarticulação do setor público, da qual as universidades não foram poupadas, podendo-se mesmo afirmar que, nos anos que precederam a posse de Lula, elas também viveram uma "reforma universitária", pautada pela crítica à presença do Estado em todas as esferas da vida nacional, o que as submeteu a políticas de austeridade, com salários arrochados e recursos para manutenção e investimento progressivamente diminuídos, de modo que o quadro geral das instituições de educação superior era (ou ainda é) de crise.

E é em um contexto de crise que passa a ser delineado o Reuni.

\section{O Reuni e a reestruturação do ensino superior publico brasileiro}

Entre os anos de 2003 e 2007 passou a ser institucionalizada a reforma do ensino superior, que ganha corpo com a adoção de um conjunto de medidas, dentre elas, o Programa de Apoio aos Planos de Reestruturação e Expansão das Universidades Federais (Reuni), instituído oficialmente em 2007 pelo Decreto-Lei de $n^{\circ}$ 6.096. Este Programa faz parte do Plano de Desenvolvimento da Educação (PDE) para o período 2001-2010, com atenção prioritária à interiorização do ensino superior público, conforme destaca o "Relatório da Comissão Constituída pela Portaria n ${ }^{\circ}$ 126/2012, sobre a Análise sobre a Expansão das Universidades Federais" elaborado pela Associação Nacional dos Dirigentes das Instituições Federais de Ensino Superior - ANDIFES:

Nesse contexto foram estabelecidos, nos últimos 10 anos, os programas de expansão do ensino superior federal, cuja primeira fase, denominada de Expansão I, que compreendeu o período de 2003 a 2007, e teve como principal meta interiorizar o ensino superior público federal, o qual contava até o ano de 2002 com 45 Universidades Federais e 148 campus/unidades. (Brasil, 2012, p. 09)

Sobre o papel da rede federal na expansão e reestruturação do ensino superior no Brasil, Soares (2013, p. 05) aponta o incremento das matrículas, com uma forte tendência a democratização deste nível de ensino a partir do Reuni:

A expansão das universidades e campi federais no período de 2003 a 2011 propiciou um crescimento de aproximadamente $111 \%$ na oferta de vagas nos cursos de graduação presencial nas instituições federais de ensino (IFES): de 109.184 para 231.530. No entanto, há uma grande diferença entre os períodos 2003-2007 e 2007-2011, sendo este último o da concepção e implementação do Reuni. Entre 2003 e 2007 houve um incremento de 30.691mil vagas (com um crescimento de $28,12 \%$ ); porém, o crescimento exponencial da expansão das vagas nos cursos de graduação presencial nas IFES aconteceu de 2007 até 2011, com um aumento de 91.655 vagas e uma taxa de crescimento de $65,53 \%$ (taxa inédita na história da evolução das vagas públicas federais no Brasil).

De fato, os números impressionam e são significativos, mas, também, deixam margem para questionamentos sobre como esta expansão tem se configurado. De acordo com Lima (2006), a educação cada vez mais deixa de ser um direito e passa a ser um serviço a gosto do mercado, sendo notório que a universidade pública brasileira tem estado na berlinda, seja para rever seus conceitos e suas funções sociais como agência formadora e produtora de conhecimentos científicos, culturais e intelectuais, seja para redefinir novas formas de administração e gestão colegiada, seja para adotar mecanismos auto-sustentáveis eficientes e com eficácia produtiva segundo a lógica mercadológica.

Não obstante, o argumento e a proposta do governo federal é o de, com o Reuni, retomar o crescimento do ensino superior público, criando condições para que as universidades promovam não só a expansão física, mas 
também a acadêmica e pedagógica da rede federal de educação superior. Nos indagamos qual o espaço destinado a discussão sobre a democratização do ensino superior neste Programa.

As Diretrizes Gerais do Reuni (2007), apontam para uma ampliação da oferta de educação superior pública considerando três aspetos principais: o aumento de vagas de ingresso, especialmente no período noturno, a redução das taxas de evasão e a ocupação de vagas ociosas.

Ao analisar os problemas do ensino superior, o documento do Reuni aponta aspectos estruturais, organizacionais e pedagógicos, apresentando "soluções" mas não discute as ações necessárias para isso:

Em suma, estreitos campos do saber contemplados nos projetos pedagógicos, precocidade na escolha dos cursos, altos índices de evasão de alunos, descompasso entre a rigidez da formação profissional e as amplas e diversificadas competências demandadas pelo mundo trabalho e, sobretudo, os novos desafios da sociedade do conhecimento são problemas que, para sua superação, requerem modelos de formação profissional mais abrangentes, flexíveis e integradores. (Brasil, 2007, p. 08)

A proposta do Governo se expressa por meio de uma retórica que esbanja a ideia de expansão, desenvolvimento e incremento da universidade pública, no que concerne em ampliar as estruturas físicas, modificar os projetos pedagógicos, aumentar o número de vagas e contratar mais profissionais qualificados. Contudo, em nossas leituras encontramos um descompasso entre a proposta preconizada pelo Governo e a efetivação da reforma do ensino superior, principalmente relativo à estrutura física e pedagógica nas Universidades e ao trabalho docente, foco do Reuni.

Não são poucos os relatos de instituições com cursos funcionando sem a necessária estrutura fisica e pedagógica. Dessa forma Lisboa (2013, p. 09) afirma que o Reuni expande a precarização nas universidades:

Enquanto o governo passa para a sociedade a falsa ideia de que as demandas do ensino superior estão sendo atendidas, a comunidade universitária sofre as consequências de uma expansão desordenada e com interrupção. Em todo o país, a constatação é a mesma: da forma como foi implantado, o Reuni (...) não cumpriu as metas que o próprio governo determinou e ainda agravou as condições de funcionamento das instituições federais de ensino superior.

No que diz respeito ao trabalho docente nas novas IES e nos novos Campi, o aumento do número de vagas e a contratação de profissionais não obedecem a uma ordem direta e pontual, como requisitos prioritários, contrariando o que está previsto em lei. No Decreto de criação do Reuni consta que o Programa tem como meta global a elevação gradual da taxa de conclusão média dos cursos de graduação presenciais para noventa por cento e da relação de alunos de graduação em cursos presenciais por professor para dezoito, ao final de cinco anos, a contar do início de cada plano. (Brasil, 2007).

Ou seja, a proposta de dobrar o número de vagas para o acesso dos alunos não implica que o número de professores contratados obedecerá este mesmo ritmo, essa mesma proporção, com condições justas e igualitárias, conforme apontava Leher e Lopes (2008, p.89), ao avaliar a evolução das matrículas nas universidades em contraposição a contratação de professores efetivos, na década anterior à implantação do Reuni:

No período de 1996 a 2006, o número de matrículas na graduação cresceu 52\%, apresentando fôlego impressionante na pós-graduação, onde dados apontam para um crescimento de $71 \%$ para o mestrado e $179 \%$ para o doutorado. Estatísticas que registram a evolução no número de funções docentes, contudo, apresentam um crescimento bem mais modesto para o mesmo período: $23 \%$ para a graduação, e $68 \%$ para a pós-graduação o que significa que os docentes credenciados na pós tiveram uma intensificação extraordinária de sua jornada de trabalho (...) Assim a carreira para o magistério superior vai assumindo novos contornos, em bases cada vez mais frágeis e cada vez mais distantes daquilo que um dia a definiu: a carreira como condição para o padrão unitário de qualidade e para a real autonomia das instituições.

Consideramos que o aumento na relação professor-aluno, provocará um maior desgaste do trabalho do docente, já configurado como precário dada às condições em que ele hoje se desenvolve.

\section{Encaminhando considerações}

Nossas analises até o momento nos permitem considerar que a Reformas ensejadas no Ensino Superior a partir dos anos 90 são parte integrante das reformas do estado e se inserem na lógica da mercantilização e dos negócios de grande retorno lucrativo, como parte de um processo mais abrangente, que transcende a simples vontade política do dirigente que governa a máquina estatal e que se encontra sob o controle direto dos países centrais. Em virtude dessa submissão política e econômica, a reforma da educação superior se constitui como uma intervenção consentida realizada pelas autoridades educacionais.

Consideramos que o Programa de Apoio aos Planos de Reestruturação e Expansão das Universidades Federais (Reuni) torna mais visível as condições precárias estabelecidas em algumas das IFES com o aumento do número de alunos que não se reflete na contratação de mais professores, implicando no aumento da jornada de trabalho docente e com a estrutura física (salas de aula, laboratórios, bibliotecas) em processo de construção.

Contudo o Reuni traz alternativas possíveis para a democratização do ensino superior, de uma vez que um expressivo número de alunos passa a frequentar o ensino superior, tornando-o menos elitista e excludente. Distinguimos que a democratização do ensino superior no Brasil está em processo, de uma vez que grupos populacionais até então excluídos da 
educação superior, começam a ser atendidos principalmente em função da política de interiorização das Instituições de Ensino Superior estabelecida por este Programa.

\section{Referências}

Afonso, A. J. (2001). Reforma do estado e políticas educacionais: entre a crise do estado-nação e a emergência da regulação supranacional. Educação $e$ Sociedade, 15-32.

Almeida, M. P. (2010). Reformas neoliberais no Brasil: a privatização nos Governos Fernando Collor e Fernando Henrique Cardoso. Tese de Doutorado. Rio de Janeiro: Universidade Federal Fluminense.

Brasil. (2003). Bases para o enfrentamento da crise emergencial das universidades brasileiras e roteiro para a reforma da universidade brasileira. Brasilia.

Brasil. (2007). Decreto $\mathrm{n}^{\circ}$ 6.096, de 24 de abril de 2007. Institui o Programa de Apoio Planos de Reestruturação e Expansão das Universidades Federais - REUNI. Brasilia, Brasil: Diario Oficial da União de 25.04.2007.

Brasil. (2012). Relatório da Comissão Constituída pela Portaria $n^{\circ} 126 / 2012$, sobre a Análise sobre a Expansão das Universidades Federais 2003 a 2012. Brasilia. Acesso em 18 de outubro de 2013, disponível em http://www.andifes.org.br

Brasil. (2014). Censo da educação superior 2012: resumo técnico. Brasilia. Fonte: Web site do INEP: http://www.inep.gov.br/superior/censosuperior

Brasil. (Agosto de 2014). Expansão da Educação Superior e Tecnológica Profissional. Fonte: http://reuni.mec.gov.br.

Bresser-Pereira, L. C. (2010). Democracia, estado social e reforma gerencial. Revista de Administração de Empresas, 50, pp. 112-116. Acesso em 30 de maio de 2015, disponível em http://www.scielo.br

Cunha, L. A. (2003). O ensino superior no octênio de FHC. Educação e Sociedade, 24, pp. 37-61. Acesso em 15 de Junho de 2015, disponível em http://www.cedes.unicamp.br

Dourado, L. F. (2002). A Reforma do Estado e as Políticas para a Educação Superior no Brasil nos anos 90. Educação e Sociedade, pp. 234-252.

Gentili, P. (2001). Universidades na Penumbra: neoliberalismo e reestruturação universitária. São Paulo: Cortez.

Gil, A. C. (2008). Métodos e Tecnicas de Pesquisa Social. São Paulo: Atlas.

Junior, J. d. (2002). A reforma do estado e da educação no Brasil de FHC. São Paulo: Xamã.

Leher, R. (2006). Um Novo Senhor da educação? A política educacional do Banco Mundial para a periferia do capitalismo. Revista Outubro, pp. 19-30.

Leher, R., \& Lopes, A. (2008). Trabalho docente, carreira e autonomia universitária e mercantilização da educação. VII Seminário Redestrado - Nuevas Regulaciones en América Latina. Buenos Aires.

Lima, C. G. (2006). Transformações nas universidades públicas no capitalismo periférico. Em S. C. (org),
Trabalho, educação e a critica marxista. Fortaleza: Imprensa Universitária.

Lisboa, C. (2013). Reuni expande a precarização nas universidades. Dossie Nacional ANDES, pp. 09-17.

Mancebo, D. (2004). A reforma universitária: reflexões sobre a privatização e mercantilização do conhecimento. Educação e Sociedade, pp. 845-866.

Marconi, M. d., \& Lakatos, E. M. (2003). Fundamentos de Metodologia Científica. São Paulo: Atlas.

Mundial, B. (1995). La enseñanza superior: Las lecciones derivadas de la experiencia. Washington.

Mundial, B. (2000). Educación Superior en los Países en Desarrollo: Peligros y Promesas. Washington.

Otranto, C. R. (2006). A reforma da educação superior no Governo Lula da Silva: da inspiração à implantação. Em J. d. Jr, J. F. Oliveira, \& D. Mancebo, Reforma Universitária: dimensões $e$ perspectivas (pp. 43-58). Campinas: Editora Alinea.

Ristoff, D. (2013). Vinte e um anos de educação superior: expansão e democratização. Rio de Janeiro: FLACSO-Brasil/GEA-ES/LPP-UERJ .

Santos, B. d. (2013). Pela mão de Alice: o social e o político na pós-modernidade. Coimbra: Almedina.

Sguissardi, W. (2008). Modelo de expansão da educação superior no Brasil: o predominio privado/mercantil e os desafios para a regulação e formação universitária. Revista Educação $e$ Sociedade, 29, pp. 991-1022. Acesso em 27 de maio de 2015, disponível em www.cedes.unicamp.br

Sguissardi, W., \& Amaral, N. C. (2000). O Banco Mundial revisa posições: quem há de pagar a conta? Revista Perspectiva, 18, pp. 65-76. Acesso em 27 de maio de 2015, disponível em https://periodicos.ufsc.br

Soares, L. T. (2013). O papel da rede federal na expansão e reestruturação da educação superior pública no Brasil. Cadernos do GEA, III, pp. 5-9.

Sobrinho, J. D. (2005). Educação superior, globalização e democratização. Qual caminho? Revista Brasileira de Educação, pp. 164-173. Acesso em 27 de maio de 2015, disponível em http://www.scielo.br

Williamson, J. (2003). Depois do Consenso de Washington: uma agenda para a reforma econômica na América Latina. Semana do Economista da FAAP. São Paulo.

\section{Agradecimentos}

Agradecemos as contribuições valiosas advindas das discussões teóricas com o Professor Doutor Almerindo Janela Gonçalves Afonso, da Universidade do Minho. 